\title{
Distribuição dos AdvÉrbios Predicativos E Adjetivos Quando Usados como Predicados ADJUNTOS*
}

\author{
Distribution of predicative adverbs and adjectives \\ when used as adjunct predicatives
}

\author{
Maria José Gnatta Dalcuche Foltran**
}

\section{INTRODUÇão}

Quando falamos a respeito de adjetivos e advérbios, há um consenso em relação ao fato de que adjetivos podem funcionar como predicados de nomes e advérbios como predicados de eventos. Numa teoria neodavidsoniana (PARSONS, 1990), verbos e adjetivos denotam conjunto de eventos e advérbios modificam o evento. Dentro dessa perspectiva, Rothstein (2004) formula uma representação para drunk e drunkenly, conforme se pode ver em (1).

\footnotetext{
(1) a. drunk $\mathrm{AP}_{\mathrm{AP}}: \lambda \mathrm{x} \lambda \mathrm{e} \cdot \operatorname{DRUNK}(\mathrm{e}) \& \operatorname{Arg}(\mathrm{e})=\mathrm{x}$

b. drunkenly ADV: $\lambda \mathbf{V P} \lambda \mathrm{e} . \mathbf{V P}(\mathrm{e})^{1} \& \operatorname{DRUNKENLY}(\mathrm{e})$
}

Este trabalho foi apresentado no VI Workshop on Formal Linguistics ocorrido em Florianópolis em agosto de 2006. Agradeço aos participantes pelos comentários. Agradeço também as observações de dois pareceristas anônimos. As falhas que ainda restaram são de minha responsabilidade.

Pós-doutorado pela Universidade Federal de Santa Catarina. Professor adjunto da Universidade Federal do Paraná.

O VP representa a denotação do VP. 
Foltran, M. J. G. D. Distribuição dos Advérbios Predicativos e Adjetivos...

Caso o adjetivo figure numa estrutura de Predicação Secundária, a propriedade que ele expressa subsiste na denotação de seu sujeito todo o tempo de desenvolvimento do evento matriz, como se pode ver em (2). Ao contrário, os advérbios não podem fazer previsão sobre argumentos sintáticos. Seu papel é modificar o evento, como mostra (3).

(2) a. O João dirigiu o carro bêbado.

b. $\exists \mathrm{e} \exists \mathrm{e}_{1} \quad \exists \mathrm{e}_{2} \quad\left[\mathrm{e}^{\mathrm{S}}\left(\mathrm{e}_{1} \cup \mathrm{e}_{2}\right]\right.$ \& $\operatorname{DIRIGIR}\left(\mathrm{e}_{1}\right)\left(\operatorname{Ag}\left(\mathrm{e}_{1}\right)=\mathrm{João} \&\right.$ Tema $\left(\mathrm{e}_{1}\right)=$ carro \& Bêbado $\left(\mathrm{e}_{2}\right) \& \operatorname{Arg}(\mathrm{e} 2)=\mathrm{J}$ oão]

(3) a. Ele respondeu a pergunta inteligentemente.

b. $\exists$ e $[\operatorname{RESPONDER}(\mathrm{e}) \& \operatorname{Ag}(\mathrm{e})=\mathrm{J}$ oão $\& \operatorname{Tema}(\mathrm{e})=\mathrm{a}$ pergunta $\&$ INTELIGENTEMENTE(e)]

A representação em (2) alude ao fato de que existe um evento que é a soma $(U)^{2}$ do evento 1 (DIRIGIR) e do evento 2 (BÊBADO) ${ }^{3}$. 0 evento 1 tem João como agente e o carro como tema. $O$ evento 2 tem João como seu argumento. Portanto, o predicado BÊBADO se aplica a João e é uma propriedade que subsiste paralelamente ao evento de dirigir ${ }^{4}$. A representação em (3), por sua vez, faz menção a um evento (RESPONDER), que tem João como agente e a pergunta como tema e diz que o evento mencionado foi feito de maneira inteligente. As representações em (2) e (3) distinguem a possibilidade de o predicado ser orientado para um participante da possibilidade de ser orientado para o evento ${ }^{5}$.

Há, no entanto, dois fatos de que essa abordagem não dá conta. 0 primeiro diz respeito aos advérbios orientados para o sujeito, já previsto em Jackendof (1972) e retomado em Ernst (2002), dentre outros. São propriedades como inteligentemente, tristemente, calmamente, etc., que são atribuídas ao sujeito e não podem ser dissociadas dele, como mostra (4).

(4) a. Ele inteligentemente respondeu à pergunta do delegado. b. Ele respondeu à pergunta do delegado inteligentemente.

\footnotetext{
Esta soma é no sentido de que eles são temporalmente independentes. Rothstein assume que a predicação secundária deve envolver uma operação de soma e não uma operação de intersecção de conjuntos. Maiores detalhes em Rothstein (2004, p. 65-68).

3 Rothstein (2004) usa aí o termo evento da forma mais genérica possível, correspondendo a eventualidade.

4 Para Rothstein (2001) é exatamente isso que caracteriza o predicado secundário: o argumento é também marcado tematicamente numa relação fora da relação de predicação secundária.

$5 \quad$ Embora considere as propriedades de advérbios orientados para o sujeito ou para agentes, Rothstein (2004, p. 65) afirma que advérbios, diferentemente de adjetivos, não podem ser predicados de argumentos sintáticos numa estrutura de predicação.
} 
A sentença em (4a) denota que ele foi inteligente ao responder a pergunta do delegado. Podemos contrapor isso ao fato de que ele poderia simplesmente ter se calado, ou seja, opomos o evento de responder a um outro evento - ficar calado. Por sua vez, $(4 \mathrm{~b})$ veicula a interpretação de que a forma como ele respondeu foi inteligente, i. e., opomos uma forma de resposta a uma outra forma de resposta, portanto, formas diversas que o mesmo evento pode tomar. Em (4a), temos um advérbio orientado para o sujeito, ou advérbio sentencial, enquanto em (4b) a leitura preferencial é a de modo.

O segundo fato que mostra que as representações em (1) são no mínimo incompletas diz respeito a um uso específico dos adjetivos, próprio das línguas românicas, conforme se pode ver em (5): o adjetivo não toma um participante do evento como seu argumento, mas o próprio evento. Para maior clareza, chamarei esses adjetivos de adjetivos adverbiais.

(5) a. O professor falou claro.

b. Ela fala difícil.

Tendo isso em vista, posso delimitar os objetivos deste artigo. Pretendo mostrar que existe um paralelo entre os predicados secundários e os advérbios (em -mente) orientados para o sujeito, como também entre os predicados secundários e os adjetivos adverbiais. Defendo, ainda, a idéia de que o fato de uma propriedade poder se alternar entre uma orientação para o evento e uma orientação para o participante é uma característica de predicados adjuntos e não dos advérbios ou adjetivos em si. Para tanto, na seção 1., apresento as características que nos permitem identificar um predicado secundário e perceber de que forma esse tipo de predicado se distingue dos advérbios orientados para o sujeito e, ao mesmo tempo, como se confunde com eles. Na seção 2., para mostrar a distribuição dos adjetivos adverbiais em relação aos predicados secundários e advérbios com -mente, parto do trabalho de Lobato (2005) e apresento argumentos contra a tese da autora. Por outro lado, mostro que a idéia de Lobato de que não há mudança categorial em relação aos adjetivos adverbiais deve ser preservada. Na seção 3., apresento algumas considerações finais.

\section{Advérbios Orientados Para o Sujeito e Predicados Secundários}

\subsection{Predicados SecundáRios}

Vou, primeiramente, destacar algumas características dos predicados secundários (PS doravante) que serão relevantes para a 
comparação que quero fazer.

PSs são construções complexas cujo sujeito é marcado tematicamente também por outro núcleo lexical.

(6) a. João chegou cansado.

b. Ele comeu a carne crua.

Em (6a), o predicado cansado predica de João que, por sua vez, recebe marcação temática também de chegou, núcleo do predicado da matriz. Como neste caso João é o sujeito, chamamos cansado de predicado secundário orientado para o sujeito. Em (6b), crua, na sua leitura predicativa, predica de carne, que também é argumento de comeu e, portanto, marcado tematicamente pelo verbo. Como carne é complemento de comeu, podemos nos referir a crua como predicado secundário orientado para o objeto.

Os PSs diferenciam-se de mini-orações (small clauses) complementos, exemplificadas em (7), pela posição sintática que ocupa e pela natureza da propriedade que selecionam. Em relação ao primeiro ponto, observa-se que a mini-oração toda é selecionada como complemento do verbo matriz e, portanto, a sentença não prescinde do predicado adjetival, ao contrário dos PSs - apresento essas propriedades selecionais nos exemplos (7), (8) e (9).

(7) a. Eu considero a Ana inteligente.

b. Eu achei este livro difícil

O complemento de considerar em (7a) é um objeto sintático complexo: a Ana inteligente, em que a Ana é sujeito do predicado inteligente. Em (7b), o verbo achei também tem como objeto o constituinte complexo este livro difícil, que exibe nitidamente uma relação de predicação. Diferentemente de (6), os adjetivos predicativos de (7), se retirados da sentença, têm efeitos sobre a sua gramaticalidade. $O$ verbo não prescinde dessa propriedade.
(8) a. *Eu considero a Ana.
b. *Eu achei este livro. (no sentido relevante)

As sentenças em (8) são agramaticais se tomarmos os verbos no sentido judicativo, como são usados em (7). Isso prova que o adjetivo predicativo é essencial em (7), mas não em $(6)^{6}$.

\footnotetext{
(2007).

Para maiores detalhes a respeito dessas construções, ver Mioto \& Foltran 
(9) a. João chegou.

b. Ele comeu a carne.

Em relação ao segundo ponto, essas duas construções se diferenciam também pelo tipo de adjetivo que aceitam: enquanto os predicados secundários selecionam predicados stage level, as mini-orações complementos aceitam apenas predicados individual level ${ }^{7}$.

(10) a. Eu considero este livro difícil.

b. ?Eu considero este livro aberto.

c. ${ }^{*}$ Eu encontrei este livro difícil ${ }^{8}$.

d. Eu encontrei este livro aberto.

Difícil, em (10a), deve ser interpretado como uma propriedade permanente de livro: é nesse sentido que dizemos tratar-se de um predicado individual level. Aberto não é uma propriedade facilmente interpretada como permanente, por isso a estranheza de (10b) - que não é marcada como totalmente agramatical por causa das nuanças de significado de considerar. No sentido avaliativo que considerar apresenta em (10a), o uso de aberto como predicado de livro não é aceitável em (10b). A agramaticalidade de (10c) se explica porque encontrar não seleciona mini-orações. O complemento de encontrar é o constituinte este livro e, portanto, o adjetivo predicativo é um predicado secundário. Difícil não é talhado para ser um predicado secundário, pois não se coloca como propriedade transitória, ou seja, não permite uma leitura stage level, pelo menos nessa estrutura.

Enumero ainda outras propriedades específicas dos PSs. O sujeito de um PS fica restrito a funções como sujeito e objeto direto da matriz: constituintes que tenham outras funções na sentença não se prestam a sujeitos de PSs. Como predicado, ele é necessariamente orientado para um participante (argumento).

PSs funcionam como diagnóstico para a distinção stage - individual level e desempenham papel importante na discussão do aspecto verbal.

PSs expressam estados que subsistem durante o tempo de referência do evento denotado pelo predicado matriz - há necessariamente, portanto, uma sobreposição temporal das eventualidades descritas.

Isso é válido pelo menos para os complementos de verbos judicativos. Não estou levando em conta aqui a leitura do adjetivo como adjunto do nome. 
Foltran, M. J. G. D. Distribuição dos Advérbios Predicativos e Adjetivos...

\subsection{ADVÉRBIos}

Quanto aos advérbios, a sua classificação é bastante controversa. Numerosas subdivisões têm sido propostas e as classes resultantes dificilmente coincidem. De modo geral, distinguem-se os predicativos dos funcionais. Não vou entrar nos detalhes dessa divisão - o que nos interessa é que os advérbios relevantes para esse estudo são os predicativos: os que têm o papel de modificar o evento e se realizam como adjunto da sentença ${ }^{9}$ - podendo se adjungir a diferentes categorias, e conseqüentemente com diferentes escopos sobre a oração. Segundo Ernst (2000), os advérbios predicativos podem ser advérbios orientados ${ }^{10}$ para o discurso, advérbios orientados para o sujeito e advérbios de modo ${ }^{11}$. Essas diferenças são reflexos do escopo dos advérbios na sentença. Mais do que a exceção é regra que um mesmo advérbio permita diferentes leituras e pertença a classes diferentes. Como já vimos em (4), o mesmo advérbio leva a interpretações diferentes.

Como os advérbios são itens lexicais não selecionados por nenhum núcleo, configurando desse modo um adjunto, eles se aproximam dos PS que não são s-selecionados, ou seja, semanticamente selecionados e também se realizam em adjunção.

O fato de os advérbios não serem necessariamente e exclusivamente orientados para o evento não é uma novidade na literatura. A denominação advérbio orientado para o sujeito remonta, até onde eu sei, a Jackendoff (1972) e é retomada por McConnell-Ginet (1982), Ernst (2000), dentre outros. Esse tipo de advérbio nos interessa mais de perto por expressar uma propriedade que é muito próxima do tipo de propriedade expressa pelos PSs. A orientação para um participante é o traço chave compartilhado por esses dois tipos de predicados adjuntos. Advérbios agentivos, como inteligentemente, estupidamente, tristemente, alegremente constituem um tipo de advérbio do nível da sentença e, segundo Himmelmann \& SchultzeBerndt (2005), eles atribuem ao agente certas características com base no evento do qual o agente participa, configurando uma avaliação sobre o agente. $O$ exemplo (4a) poderia ser parafraseado por (11).

(11) Foi inteligente da parte do João responder à pergunta do advogado.

\footnotetext{
Ilari et al. (1990, p. 89) define advérbios predicativos como predicados de
segundo grau, i.e., predica "uma propriedade da qualidade ou ação que se atribui ao sujeito". Advérbios orientados para o discurso são aqueles que veiculam uma atitude do falante em relação ao evento, como infelizmente, certamente, etc.

A respeito dessa classificação, ver também Ilari et al. (1990) e Ernst (2002).
} 
Resumindo, podemos dizer que PSs e advérbios orientados para o sujeito são predicados adjuntos, não selecionados pelo predicado matriz e compartilham da propriedade de serem orientados para um argumento. No entanto, diferem em relação a outras propriedades:

a) semanticamente, os PSs não veiculam avaliação do comportamento do agente, como o fazem os advérbios em foco.

b) PSs podem tomar argumentos que não sejam agentes, conforme (12).

(12) Ele tomou o café quente.

c) PSs também não podem ser interpretados como predicados de todo um estado de coisas. Tendo como base (4) e (11), (13a), por exemplo, não pode ser interpretado como (13b).

(13) a. João respondeu à pergunta bêbado.

b. ??Foi bêbado da parte do João responder à pergunta.

d) Advérbios orientados para o agente e PSs diferem também quanto ao posicionamento na sentença: os advérbios orientados para o agente só ocorrem em posição pré-verbal, enquanto PSs ocorrem em posição final de sentença.

Predicado Secundário, como o que ocorre em (13a), acarreta, como já vimos, que os dois estados de coisas - responder à pergunta e estar bêbado - se sobrepõem no tempo: $o$ ato de responder não está ligado ao estado de estar bêbado. $O$ advérbio, por outro lado, veicula uma ligação causal ou factual com o evento ${ }^{12}$ mais direta. Em (14), a atividade denotada pelo predicado principal e a condição emocional ou psicológica do sujeito estão correlacionadas: é a forma de agir de João, o modo como deixou a festa, que me permite avaliar o seu estado, ou seja, a forma como o sujeito se engaja na atividade denotada pelo predicado principal sugere algo sobre $o$ seu estado. Portanto, essa relação vai além da mera sobreposição temporal.

(14) O João furiosamente deixou a festa.

Podemos usar de paráfrases para deixar mais nítidas as interpretações conferidas a essas construções. Em Foltran (1999), assumi que a paráfrase de uma construção de PSs é a que está em (15), respectivamente para (12) e (13a). 
Foltran, M. J. G. D. Distribuição dos Advérbios Predicativos e Adjetivos...

(15) a. O café estava quente quando ele o tomou.

b. O João estava bêbado quando respondeu à pergunta ${ }^{13}$.

Ao contrário dos PSs, as construções adverbiais podem ser parafraseadas com uma oração em que se estrutura o elemento correspondente à função adverbial como predicado principal, ou por uma construção atributiva em que o elemento correspondente ao advérbio é um modificador do nome. Isso nos mostra o comportamento diferente dos exemplos em (16), conforme (17) e (18).

(16) a. João respondeu à pergunta inteligentemente. b. O João respondeu à pergunta bêbado.

(17) a. A resposta à pergunta foi inteligente. b. A inteligente resposta às perguntas.

(18) a. *A resposta às perguntas foi bêbada. b. *A bêbada resposta às perguntas.

Retomando, os advérbios em foco neste trabalho podem ter uma interpretação orientada para o sujeito quando adjungidos no nível da sentença e uma interpretação de modo quando adjungidos no nível do $\mathrm{VP}^{14}$. As paráfrases para essas interpretações são (11) e (17a e b) respectivamente. Já um PS tem como paráfrase as sentenças em (15). A princípio, estou dizendo, portanto, que esses predicados são interpretados de maneira diferente. No entanto, dependendo da propriedade em jogo, essa diferença não é tão nítida assim. Por exemplo, quando utilizamos advérbios como calmamente ou alegremente, em contraposição a adjetivos como calmo e alegre, a diferença entre advérbios orientados para o agente e predicados secundários não é mais tão clara. Observemos os exemplos.

(19) a. O professor calmamente saiu da sala.

b. O professor saiu da sala calmamente.

c. O professor saiu da sala calmo.

(20) a. ??Foi calmo da parte do professor sair da sala.

b. O sair da sala foi calmo.

c. O calmo sair da sala.

d. O professor estava calmo ao sair da sala.

Por enquanto, não vou discutir isso. 
(21) a. A Maria canta alegremente.

b. A Maria canta alegre.

(22) a. O cantar da Maria é alegre.

b. $O$ alegre cantar da Maria.

c. A Maria está alegre ao cantar.

As interpretações aceitáveis em (20) podem ser conferidas a qualquer sentença de (19). O mesmo posso afirmar de (22) em relação a (21). A propriedade de ser calmo só pode ser inferida por meio das atitudes do professor e pela forma como ele realiza ou encena ou "performatiza" a eventualidade. A mesma coisa se pode dizer de alegre. Portanto, a interpretação dessas construções pode se sobrepor. Ao testar a intuição de falantes em relação a (21), percebi que para eles a diferença não é nítida. Himmelmann \& Schultze-Berndt (2005) chamam a atenção para o fato de que as sentenças do inglês em (23) correspondem no alemão à sentença em (24).

(23) a. Claire left the room angry.

b. Claire left the room angrily.

(24) Claire hat wünted das Zimmer verlassen ${ }^{15}$.

Ou seja, em alemão não há uma diferença morfológica entre o adjetivo e o advérbio de modo e tanto (23a) como (23b) corresponderiam a (24). Os autores dizem ainda que os falantes não interpretam (24) como uma sentença semanticamente ambígua, mas antes uma sentença que apresenta vagueza em relação aos diferentes significados do inglês. Acho que poderíamos afirmar exatamente isso dos exemplos (19) e (21): eles são vagos em relação às interpretações apresentadas em (20) e (22).

o que podemos depreender dessa exposição é que a afirmação de que advérbios operam sobre eventos enquanto adjetivos predicam de argumentos fica comprometida ao compararmos estruturas de PSs com sentenças com advérbios orientados para o agente ou mesmo com alguns advérbios de modo. Portanto, a representação em (1) não conta toda a história que precisa ser contada.

\footnotetext{
\& Schultze-Berndt $(2005$, p. 2).
} 


\section{Adjetivos Adverbiais e Predicados Secundários}

Vamos passar agora ao segundo fato mencionado no início deste trabalho: os adjetivos adverbiais (AA daqui em diante) exemplificados em (5) e retomados aqui como (25).

(25) a. O conferencista falou claro. b. Ela fala difícil.

As abordagens mais tradicionais ${ }^{16}$ assumem que, nesses casos, $o$ adjetivo passa a desempenhar uma função adverbial, ou seja, passa a ser invariável e apresenta a interpretação de modificador do evento, tendo o valor específico de um advérbio de modo. Outras abordagens, como a de Hummel (s.d. apud LOBATO, 2005) analisa esses adjetivos como casos de conversão, o que resulta em uma homofonia criada a partir de um processo morfológico. Assim, esses itens teriam o estatuto morfológico de advérbios. Basílio (1992) compartilha dessa hipótese, ou seja, a de que os adjetivos como os que aparecem em (25) assumem as propriedades dos advérbios, o que implica admitir a existência de dois itens homófonos: um adjetivo e o outro advérbio. Lobato (2005), no entanto, dá um tratamento diferente, que passo a apresentar na seqüência.

A autora descreve três tipos de ambientes para atributos com ou sem -mente: a) ambientes em que só a forma sem -mente é permitida, b) ambientes em que só a forma com -mente é permitida e c) ambientes em que as duas formas são licenciadas. O objetivo de Lobato é argumentar a favor da hipótese de que os atributos destacados em (25) são verdadeiros adjetivos em uso adjetival, porque predicam de propriedade nominal. Quando só a forma sem -mente é licenciada, a predicação recai sobre forma nominal não manifesta. Para este caso, apresenta os exemplos em (26) e (27).

(26) a. Ela fala alto/baixo.

b. *Ela fala altamente/baixamente.

(27) a. Ela leu bonito esse trecho. Ela canta essa música bonito.

b. *Ela leu bonitamente esse trecho/

*Ela canta essa música bonitamente ${ }^{17}$.

Dentre essas abordagens, cito a de Cunha e Cintra (1985, p. 257).

Estes exemplos equivalem aos exemplos (14) e (15) de Lobato. 
Para a autora, verbos como ler e falar dizem respeito ao uso da voz, elemento que está presente na estrutura léxico-funcional do verbo em questão. Assim, o atributo indicaria uma propriedade da voz do indivíduo. Em exemplos como (28), a propriedade nominal de que o atributo predica é um objeto implícito.

(28) a. Elas sorriram amarelo, dormem pesado/cheiram gostoso.

b. *Elas sorriram amarelamente/ dormem pesadamente/ cheiram gostosamente ${ }^{18}$.

Para o segundo tipo de ambiente - uso categórico do atributo com -mente -, a autora assume que o atributo tem como o escopo da predicação a relação proposicional, que inclui sujeito e o tempo verbal. Este ambiente prevê exemplos como os em (29)-(31).

(29) a.Infelizmente, ela não leu o poema.

b. \#Infeliz, ela não leu o poema.

(30) a. Joana disse que, felizmente, Maria veio.

b. \#Joana disse que, feliz, Maria veio.

(31) a. Sinceramente/Honestamente ela não virá. * Sincero/* Honesto, ela virá ${ }^{19}$.

Finalmente, os atributos alternantes - aqueles em ambientes em que as duas formas são permitidas - se dividem em diferentes classes: os atributos sem -mente predicam do ato verbal ou do produto do evento, sempre sem tempo nem sujeito envolvidos, ou, ainda, de propriedade nominal integrante da definição semântica do verbo. Para Lobato, os exemplos em a de (32) a (34) exemplificam os casos que descreve: os atributos podem predicar do ato verbal (o falar, o cantar, etc.), ou do produto do evento (a fala, o canto, etc.), ou ainda de propriedade nominal do verbo (a voz):

(32) a. Maria fala manso/nervoso/ lento/pausado.

b. Maria fala mansamente,nervosamente,lentamente...

(33) a. Maria canta desafinado.

b. Maria canta desafinadamente.

\footnotetext{
18 Exemplo (20) de Lobato.

19 Exemplos (23), (24) e (25) de Lobato.
} 
Foltran, M. J. G. D. Distribuição dos Advérbios Predicativos e Adjetivos...

(34) a. Ela canta essa música lindo. I

Ela canta essa música lindamente.

Ela canta lindo essa música. /

Ela canta lindamente essa música. ${ }^{20 / 21}$

Lobato afirma ainda que se o adjetivo expressa uma propriedade do sujeito, não poderá ocorrer como AA. Nestes casos, sempre usamos a contraparte em -mente.

(35) a. Ela falou orgulhosamente de seus filhos.

b. *Ela falou orgulhoso de seus filhos.

(36) a. Maria fez isso astuciosamente/ engenhosamente/ subalternamente/ soberanamente.

b. *Maria fez isso astucioso/ engenhoso/subalterno/ soberano.

(37) a. A universidade resistiu resistiu heróico.

b. *A universidade heroicamente.

(38) a. Maria assistiu à aula atentamente.

b. *Maria assistiu à aula atento.

(39) a. Maria leu a carta cuidadosamente.

b. *Maria leu a carta cuidadoso. ${ }^{22}$

\section{Essa abordagem apresenta algumas vantagens:}

a) Não precisamos nenhuma alteração categorial - o que é adjetivo é adjetivo e se distingue morfologicamente dos advérbios, e isso é interessante para qualquer teoria gramatical.

b) Grande parte dos exemplos com AA ocorrem com verbos monoargumentais e, dentre esses, são principalmente os intransitivos, em oposição aos inacusativos, que favorecem o uso do AA. Isso corrobora a análise de Lobato, pois verbos intransitivos são propensos a terem um objeto cognato ou objeto não manifesto, latente na estrutura. É essa justamente a interpretação apresentada por Lobato - uma predicação sobre o produto do evento (falar uma fala, andar uma andada, e assim por diante).

c) Os AA não têm mobilidade na sentença - ao contrário da

\footnotetext{
Exemplos (57)-(59) de Lobato.

Hummel (2000) atesta que o uso do adjetivo neste contexto é mais comum no PB que no PE e o uso da forma com -mente e sem -mente está ligado a uma diferença de registro. $22 \quad$ Exemplos (40) a (44) de Lobato. 
propriedade apresentada pelos advérbios de poder participar da estrutura em diferentes posições. Isso explica o comportamento diferenciado desses itens, como mostram (40) e (41).

(40) a. Cuidadosamente a Joana retirou o quadro da parede.

b. A Joana cuidadosamente retirou o quadro da parede.

c. A Joana retirou o quadro da parede cuidadosamente.

(41) a. *Claro o conferencista falou.

b. ${ }^{*} \mathrm{O}$ conferencista claro falou.

c. O conferencista falou claro.

Por outro lado, podemos arrolar alguns problemas. O principal deles é o de explicitar melhor essa propriedade nominal não manifesta predicada pelo adjetivo. Da forma como Lobato coloca, qualquer verbo teria uma propriedade desse tipo, já que engloba-se aí o ato verbal, um produto do evento ou propriedade integrante da definição semântica do verbo. Ou seja, podemos inferir de qualquer verbo uma ou mais dessas condições e não há como diferenciar uma predicação feita pelas formas com -mente ou sem -mente. Explicando melhor, numa sentença como (42a), pode-se dizer que a forma vagarosamente predica também do ato verbal (o caminhar é vagaroso).

(42) a. Aquela senhora caminhava vagarosamente.

b. *Aquela senhora caminhava vagaroso.

Se o ato verbal é uma forma nominal, deveria ser possível a predicação com a forma sem -mente, mas não é. Quando usamos o adjetivo, como em (42b), ele funciona como PS (aquela mulher caminhava vagarosa). Por que $o$ adjetivo aí não predicaria dessa propriedade nominal?

Outra questão que deve ser levada em conta é a de que é possível termos um AA com objeto direto manifesto, como mostro em (43).

(43) a. Eles encontraram fácil o livro.

b. Ela leu bonito esse texto.

c. Maria canta essa ópera regular. ${ }^{23}$

Parece óbvio que fácil não predica de livro em (43a), nem bonito predica de esse texto em (43b). Teríamos que dizer que, além dos complementos realizados, haveria outros na estrutura léxico-funcional

${ }^{23}$ Os exemplos (43)b e (43)c são exemplos de Lobato. 
desses verbos que serviriam de base para a predicação do adjetivo ${ }^{24}$. Essa generalização é tão poderosa que perde sua eficácia. Há um exemplo usado por Lobato, apresentado em (44), que é exemplar nesse caso: apesar de haver um objeto não manifesto - a comida -, o predicado escondido não se aplica a ele. Lobato assume que, neste caso, a predicação se dá sobre o ato verbal $-o$ ato de comer.

(44) Ela come escondido.

Ainda em relação a esse aspecto, se quiséssemos sustentar a generalização proposta por Lobato, teríamos que explicar por que (45) é agramatical. A autora assume que, neste caso, só haveria predicação da relação proposicional, mas não explica por quê.

(45) *Ela viveu modesto em Paris.

Temos aí todas as condições para a ocorrência do AA: podemos pensar em viver uma vida, ou seja, uma vida estaria na estrutura léxicofuncional; modesto seria uma propriedade compatível com esse complemento e pode subespecificar viver, ou seja, seria uma maneira de viver. No entanto, a regra não funciona e temos que usar a contraparte em -mente, sem poder ter, inclusive, a forma alternante.

Além disso, a observação de Lobato de que uma propriedade do sujeito não pode ocorrer como AA (exemplos de (35) a (39)) também pode ser contrariada com exemplos do tipo (46).

(46) a. O menino dorme tranqüilo.

b. As crianças dormem tranqüilo.

(46a) é ambígua entre uma leitura em que o adjetivo funciona como PS e outra em que ele funciona como AA. A possibilidade de termos aí um AA é comprovada por (46b): o adjetivo não concorda com o sujeito e estaria, portanto, predicando do "ato verbal". O que quero mostrar é que, apesar de não ser comum, pode haver competição entre PSs e AAs, como também há entre PSs e advérbios em -mente. De modo geral, a observação de Lobato se comprova: nos exemplos b de (35) a (39), se fizermos a

\footnotetext{
$24 \quad$ Estou ciente de que Lobato (2005, p. 7), como ela mesmo afirma, trata "esses objetos como parte da estrutura léxico-conceptual dos verbos e não da estrutura sintática da oração". Mas, até onde sei, na estrutura léxico-conceptual também devem estar os argumentos que se manifestam na estrutura sintática.
} 
concordância do adjetivo com o sujeito das sentenças, teremos construções de predicação secundária bem formadas em todos os casos.

Em relação à falta de mobilidade dos AA, exemplificada em (41), podemos acrescentar que a mobilidade é própria dos advérbios terminados em -mente. Outros advérbios também sofrem restrições a ocupar diferentes lugares na sentença. Portanto, se quisermos considerar os AAs advérbios, a falta de mobilidade não seria um impedimento.

$$
\begin{aligned}
& \text { (47) a. Ele falou bem. } \\
& \text { b. *Bem ele falou. } \\
& \text { c. *Ele bem falou. }
\end{aligned}
$$

Finalmente, se aplicarmos os testes de paráfrases apontados na seção anterior, veremos que uma construção com AA seria parafraseada adequadamente por sentenças que parafraseiam construções com advérbios e não construções com PSs. Fica, assim, difícil de negar um uso adverbial, expressando modo ou maneira, para esses adjetivos.

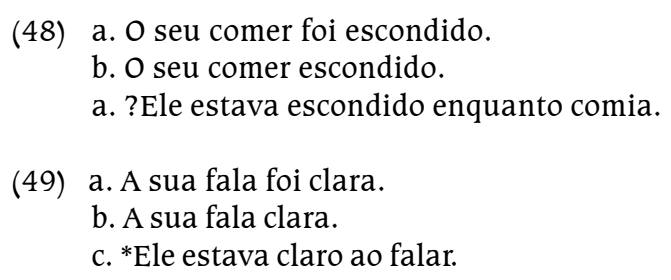

\section{CONCLUSÃo}

Apesar de argumentar contra a tese de Lobato, considero a decisão da autora de assumir os AAs como adjetivos a mais acertada. No entanto, não há como sustentar que seja um adjetivo em um típico uso adjetival. Neste trabalho, questiono as afirmações de que advérbios se voltam exclusivamente para eventos e adjetivos exclusivamente para argumentos. Podemos elencar uma série de exemplos em que a diferença no uso dessas categorias, de acordo com sua distribuição e interpretação, não são nada nítidas. Pode-se dizer que há uma sobreposição desses predicados, o que impede a co-ocorrência deles, como podemos ver em (50).

(50) a. Maria canta feliz. (predicado secundário)

b. Maria canta certo. (adjetivo adverbial)

c. Maria canta tranqüilamente. (advérbio de maneira)

d. *Maria canta feliz certo.

e. *Maria canta feliz tranqüilamente. 
É importante esclarecer que, a partir dos fatos apresentados aqui, não se pode inferir que a fronteira entre adjetivos e advérbios é sempre pouco clara. Atribuo as sobreposições atestadas pelos exemplos aos contextos em que adjetivos e advérbios são predicados realizados em adjunção, que é como classifico os advérbios orientados para o sujeito, predicados secundários e adjuntos adverbiais.

Antes de finalizar, cabe ainda observar que, dentre o que normalmente se coloca como exemplos de AA, pode haver elementos de natureza diversa envolvidos. Chamo a atenção para alguns como rápido, direto, e talvez até o fácil que usei como exemplo neste texto. Essa impressão vem do fato de que esses itens se combinam muito facilmente com diferentes verbos, o que não acontece com outros adjetivos.

\title{
RESUMO
}

Este artigo apresenta a distribuição de advérbios predicativos e predicados secundários no português do Brasil. Mostra primeiramente que advérbios orientados para o sujeito compartilham com predicados secundários o traço de poder ser orientado para um participante do evento e não exclusivamente para o evento, como propõem as teorias semânticas de eventos. 0 artigo apresenta também o comportamento dos adjetivos usados adverbialmente e argumenta, contra Lobato (2005), que não há como negar o valor adverbial desses adjetivos. Argumento ainda que o comportamento de advérbios e adjetivos se sobrepõe somente quando são predicados adjuntos. Palavras-chave: advérbio predicativo; adjetivo adverbial; predicado secundário.

\begin{abstract}
This paper presents the distribution of predicative adverbs and secondary predicates in Brazilian Portuguese. It shows that subject-oriented adverbs share with secondary predicates the feature that they can be participant-oriented, contrary to the belief that adverbs are deemed to be exclusively eventoriented. The paper also shows the behaviour of adjectives in an adverbial use and claims, against Lobato 2005, that this adverbial value cannot be denied. It also claims that the common features to both adverbial and adjectives overlap only when they are adjunct predicates.

Key-words: predicative adverbs; adverbial adjective; secondary predicate.
\end{abstract}




\section{REFERÊNCIAS}

BASÍLIO, M. Flutuação categorial de base adjetiva no português falado. In: ILARI, R. (Org.). Gramática do Português Falado: Níveis de Análise Lingüística. Campinas: Editora da Unicamp, 1992. v. II.

CUNHA, C.; CINTRA, L. Nova Gramática do Português Contemporâneo. 2. ed. Rio de Janeiro: Nova Fronteira, 1985.

ERNST, T. Manners and Events. In: TENNY; PUSTEJOVSKY. Events as grammatical objects. Stanford: CSLI Pub, 2000.

The syntax of adjuncts. Cambridge: Cambridge University Press, 2002.

FOLTRAN, M. J. As construções de predicação secundária no português do Brasil: aspectos sintáticos e semânticos. Tese (Doutorado) - Universidade de São Paulo, 1999.

Predicados secundários: restrições semânticas. Revista Letras, n. 58, Curitiba: Editora da UFPR, p. 265-278, 2002.

HIMmELmAnN, N. P.; SCHUlTZE-BERNDT, E. Secondary Predication and Adverbial Modification: The tipology of depictives. Oxford: Oxford University Press, 2005.

HUMMEL, M. Considerações sobre os tipos ele fala esquisito e ela chega cansada no português coloquial e literário do Brasil e de Portugal. COLóQUIO INTERNACIONAL: A investigação do Português em África, Ásia, América e Europa: balanço e perspectivas. Berlin, 2000.

ILARI, R. et al. Considerações sobre a posição dos advérbios. In: CASTILHO, A. T. (Org.). Gramática do Português Falado: A Ordem. Campinas: Ed. da Unicamp, 1990. v. I.

JACKENDOFF, R. Semantic interpretation in generative grammar. Cambridge (MA): MIT Press, 1972.

LOBATO, L. Sobre o Suposto Uso Adverbial de Adjetivo: a questão categorial e as questões da variação e da mudança lingüística. CONGRESSO INTERNACIONAL DA ABRALIN. Brasília, 2005.

MC CONELL-GINET, S. Adverbs and Logical Form. Language , n. 58, p. 144-184, 1982.

MIOTO, C.; FOLTRAN, M. J. A favor de small clauses. Cadernos de Estudos Lingüísticos, Campinas: Editora da Unicamp, 2007. A sair.

PARSONS, T. Events in the semantics of English. Cambridge (MA): MIT Press, 1990.

ROTHSTEIN, S. Predicates and their subjects. Dordrecht: Kluwer Academic Press, 2001.

2004.

. Structuring Events: a study in the semantics of lexical aspect. Oxford: Blackwell, 